\title{
Corneal Imaging and Densitometry Measurements in Juvenile and Adult Keratoconus Patients to Evaluate Disease Progression and Treatment Effects After Corneal Cross-Linking
}

This article was published in the following Dove Press journal: Clinical Optometry

\author{
Khaled Alzahrani $\mathbb{D}^{1-3}$ \\ Hanan Mofty ${ }^{1,4}$ \\ Emily YC Lin' \\ Fiona Carley ${ }^{2}$ \\ Arun Brahma ${ }^{2}$ \\ Debbie Morley ${ }^{2}$ \\ Susmito Biswas ${ }^{2}$ \\ M Chantal Hillarby'
}

'Division of Pharmacy and Optometry, School of Health Sciences, University of Manchester, Manchester, UK; ${ }^{2}$ Research Department, Manchester Royal Eye Hospital, Manchester, UK; ${ }^{3}$ King Fahad Armed Forces Hospital, Jeddah, Saudi Arabia; ${ }^{4}$ Optometry Department, College of Applied Medical Science, King Saud University, Riyadh, Kingdom of Saudi Arabia
Correspondence: Khaled Alzahrani Optometry Division, Opthalmology Department, King Fahad Armed Forces Hospital, P O Box 986, Jeddah 21I59, Saudi Arabia

Email khaledod@gmail.com

\begin{abstract}
Purpose: In this study densitometry software for the Oculus Pentacam was used to investigate the treatment outcomes of corneal cross linking (CXL) in adult and juvenile keratoconus $(\mathrm{KCN})$ patients. Densitometry measurements were taken before and after treatment and followed up for one year.

Methods: A comparative study was carried out at Manchester Royal Eye Hospital. Corneal densitometry measurements collected before and after CXL treatment for 32 eyes from $\mathrm{KC}$ patients, aged between 12 and 39, were divided to 2 groups 13-18 years (juvenile group) and 19-39 years (adult group) and analysed and compared to pre and post treatment at 3, 6 and 12 months for each group and between both groups.
\end{abstract}

Results: Analysis of densitometry measurements found higher corneal densitometry after CXL which peaks at three months post treatment in both groups. There was significant diversity in corneal densitometry measurements in the stromal zone 0-2 and 2-6 $\mathrm{mm}$ for all layers except the posterior layer for both groups $(\mathrm{P}<0.05)$. Significantly increased densitometry value was found higher in the juvenile group at six months in the central $(\mathrm{P}=0.006)$ and posterior $(\mathrm{P}=0.004)$ layers for zone $0-2 \mathrm{~mm}$. The same layers differed significantly also in the $2-6 \mathrm{~mm}$ zone in all layers $(\mathrm{P}=0.01)$. One year post treatment the same significant increased densitometry level was seen in the juvenile group in the $0-2 \mathrm{~mm}$ zone of the central $(\mathrm{P}=0.007)$ and posterior layers $(\mathrm{P}=0.01)$, as was the $2-6 \mathrm{~mm}$ zone $(\mathrm{P}=0.04)$. However, no significant difference was found between pre and post treatment for best corrected visual acuity (BCVA), central corneal thickness (CCT) and thinnest area between both groups. A significant difference was found between pre and post treatment for best corrected visual acuity (BCVA), in the adult group at 6 and 12 months posttreatment from pre-treatment $(\mathrm{P}=0.02, \mathrm{P}=0.16)$ respectively.

Conclusion: Corneal clarity post CXL treatment in the juvenile group differed significantly from the adult group. Both groups showed increased haze at 3 months post treatment but the adults showed improvement over the next 9 months. In contrast, the juvenile group showed higher densitometry readings at both 6 and 12 months post treatment in comparison to adult group. The reasons for this remain unclear.

Keywords: collagen cross-linking, densitometry, keratoconus, juvenile

\section{Introduction}

Collagen cross-linking (CXL) is one of the treatment options that has led to a reduction in corneal transplantations for keratoconus $(\mathrm{KCN}) .{ }^{1}$ Simplicity and lower cost along with its good results makes CXL the most popular treatment for 
stabilizing disease progression. The key to success is a lasting stiffening effect and a halt to further thinning as well as preventing long-lasting side effects. ${ }^{2} \mathrm{CXL}$ is an approach with the objective of elevating corneal biomechanical stability and rigidity. ${ }^{3,4}$ The process entails debriding the corneal epithelium within a central zone diameter of $6-7 \mathrm{~mm}$ followed by application of riboflavin $0.1 \%$ solution following by corneal radiation at $370 \mathrm{~nm}$ of ultraviolet-A light. This radiation triggers riboflavin, hence producing reactive oxygen species that enables the formation of extra covalent bonds (situated amid collagen fibrils) in the cornea stroma. The level of irradiation penetrating the corneal endothelium, retina, and lens is considerably less than the harmful threshold. ${ }^{5}$

The cornea's mechanical strength is reduced in keratoconus. In addition to load values, this is valid equally for stress values, typically the load values that are cross-sectional area segmented. A distinctive corneal haze is often detected in clinical evaluations after CXL. ${ }^{6}$ The literature reveals how CXL's depth and haze formation is capable of being viewed by simply employing the separation line observed in the corneal stroma ${ }^{7}$ or via ranking slit lamp's cornea haze. ${ }^{8}$ Additionally, further confirmation of cornea haze after CXL has been delineated utilizing confocal microscopy. ${ }^{9,10}$

Oculus Pentacam (Oculus Inc., Wetzlar, Germany), a device that employs the Scheimpflug principle to focus images at the anterior segment. It has a rotating camera that takes close to 50 anterior segment images in 2 seconds thus providing a quantifiable measurement of corneal clarity. This study aims to evaluate cross-linking procedure outcome by using corneal densitometry to quantify haze in both adult and juvenile keratoconus.

\section{Participants and Methods}

This is a prospective comparative and non-randomised cross-sectional study and was approved by Central Manchester University Hospitals NHS Foundation Trust, Manchester, UK, and NREC local ethics committee.

Informed consents were obtained from all participants after careful explanation of the nature of the study. A parent or legal guardian provided written informed consent for any participant under the age of 18 years. The study adheres to the principles of the Declaration of Helsinki. Patients who were age more than 12 years old at the time of CXL treatment and were happy to be included in the study for a one year follow-up post treatment were selected. Clinical notes were examined where relevant information were recorded for descriptive data analysis.
Post-treatment parameters including best-corrected visual acuity in LogMAR (BCVA), refraction and relevant clinical details were extracted from the clinical notes for data analysis. Post-operative data of $\mathrm{CD}$ and central corneal thickness (CCT) were measured by the Oculus Pentacam.

\section{Treatment Procedures}

The same technique was carried out for all patients following a standard protocol for corneal CXL. ${ }^{3}$ Topical anaesthesia of the cornea was obtained using Benoxinate $0.4 \%$. After a lid speculum was inserted, $20 \%$ alcohol was applied for 20 seconds to debride the epithelial layer. Ultrasound pachymetry was used to check central corneal thickness after debridement. If CCT was more than $400 \mathrm{um}$ the process continued to be applied by one drop of $0.4 \%$ hypotonic riboflavin applied to the cornea every minute for 20 mins. The centre of the cornea was then irradiated with ultraviolet-A $(9.86 \mathrm{~mW}-U V A)$ for 10 mins (UVX 1000 system; IROC Innocross AG, Zurich, Switzerland). Following the CXL procedure, all patients receive a topical antibiotic with appropriate pain relief and dexamethasone $1 \%$ for a period of 4-8 weeks post treatment.

\section{Pentacam Imaging}

Pentacam images are routinely used clinically as a corneal diagnostic measurement to assess disease progression in keratoconus patients. A good single image of the cornea was taken at each visit both pre and post treatment at routine clinic visits at 3,6 and 12 months post treatment. For the purpose of analysis $\mathrm{CD}$, the cornea was dividing into 3 layers (anterior, central and posterior) and 3 concentric zones $(0-2,2-6$ and $6-10 \mathrm{~mm})$.

The measurements from the Pentacam images were compared to other measurements such as visual acuity to determine if each measurement can provide useful information on the progression of the disease and the subsequent improvement after CXL.

\section{Statistical Analysis}

Data analyses were performed using IBM SPSS Statistics for Mac, Version 23.0. Armonk, NY: IBM Corp and Graph pad prism7 for Windows was used for statistical analysis. Normality of data was assessed with the Shapiro-Wilks test. Data were presented for each follow-up as the mean \pm standard deviation (SD) at baseline, 3 months, 6 months, and 12 months. Mann-Whitney test was used to analyse to compare both groups. Paired Wilcoxon-signed rank was used to analyse follow-ups as compared to the baseline. A P value $<0.05$ considered statistically significant. 


\section{Results}

There were a total number of 32 eyes from 31 patients (14 eyes in the juvenile group and 18 eyes in the adult group). Male to female ratio was 20:12 and there were 17 right eyes and 15 left eyes. The mean and standard deviation of the age at treatment time was 16.0 (1.79) for the juvenile group and 26.2 (7.67) for the adult group. Mean and SD of $\mathrm{CD}$ for different layer and zone for both groups have been summarized in Tables 1 and 2.

\section{Adult Group}

Figure 1A illustrates the differences found between post treatment measurements and the different zones of the cornea. A significant statistical difference in CD was found between pre-treatment and 3 months post treatment period. This was found at the anterior $(\mathrm{P}=0.01)$ and central $(\mathrm{P}=0.02)$ layers of corneal zone $0-2$. Another statistical significant difference was found within the $2-6 \mathrm{~mm}$ zone at the anterior layer $(\mathrm{P}=0.003)$, and the central layer $(\mathrm{P}=0.02)$. However, the difference between pre-treatment and post treatment at 6 and 12 months was not statistically significant $(\mathrm{P}>0.05)$.

When we compared the result of post treatment at 3 months with post treatment at 6 months statistically significant differences in $C D$ were found in zone $0-2 \mathrm{~mm}$ of the anterior layer $(\mathrm{P}=0.03)$ central layer $(\mathrm{P}=0.03)$. For the 2-6 $\mathrm{mm}$ zone, significant statistical difference was found in the anterior layer (P0.04) and the central layer $(\mathrm{P}=0.008)$. Also, at zone $6-10 \mathrm{~mm}$, the study found statistical difference in $\mathrm{CD}$ for anterior $(\mathrm{P}=0.01)$ and central $(\mathrm{P}=0.04)$. Comparing results between 3 months and 12 months, CD statistically differed between both groups at $0-2 \mathrm{~mm}$ zone for the central layer $(\mathrm{P}=0.01)$, in the $2-6 \mathrm{~mm}$ zone of the anterior layer $(\mathrm{P}=0.02)$ and central layer $(\mathrm{P}=0.01)$ and in the $6-10 \mathrm{~mm}$ zone anterior $(\mathrm{P}=0.01)$ and central $(\mathrm{P}=0.04)$. No statistical differences in $\mathrm{CD}$ were present when we compared its value between 6 and 12 months post treatment.

Table I Mean and SD for Corneal Densitometry at Pre-Treatment and Post Treatment at 3, 6, 12 Months for Adult Group

\begin{tabular}{|c|c|c|c|c|c|}
\hline \multirow[t]{2}{*}{ Zone } & \multirow[t]{2}{*}{ Layers } & \multirow[t]{2}{*}{ Pre CXL, Mean (SD) } & \multicolumn{3}{|c|}{ Post CXL, Mean (SD) } \\
\hline & & & 3 Months & 6 Months & I 2 Months \\
\hline \multirow[t]{3}{*}{$0-2 \mathrm{~mm}$} & Anterior & $24.7(8.3)$ & $29.5(7.1)$ & $25.9(7.7)$ & $24.9(3.1)$ \\
\hline & Central & I8.4 (2.8) & $20.9(3.3)$ & $18.3(2.4)$ & $18.5(1.8)$ \\
\hline & Posterior & $12.6(0.7)$ & I3.I (I.8) & $12.5(1.2)$ & $12.7(1.4)$ \\
\hline \multirow[t]{3}{*}{$2-6 \mathrm{~mm}$} & Anterior & $20.1(6.1)$ & $24.3(6.5)$ & $21.4(6.8)$ & $19.8(2.0)$ \\
\hline & Central & $16.0(2.8)$ & $15.8(2.4)$ & $16.0(1.7)$ & $18.3(2.7)$ \\
\hline & Posterior & $12.2(0.5)$ & $12.6(1.1)$ & II.8 (I.I) & $12.2(1.1)$ \\
\hline \multirow[t]{3}{*}{$6-10 \mathrm{~mm}$} & Anterior & I8.5 (4.8) & $22.0(6.4)$ & $19.9(6.6)$ & $18.5(2.9)$ \\
\hline & Central & $15.0(2.2)$ & $16.5(2.6)$ & I5.4 (2.6) & $15.8(2.1)$ \\
\hline & Posterior & $12.9(1.4)$ & I3.4 (2.0) & I3.I (I.8) & I3.3 (I.8) \\
\hline
\end{tabular}

Table 2 Mean and SD for Corneal Densitometry at Pre-Treatment and Post Treatment at 3, 6, and I2 Months for Juvenile Group

\begin{tabular}{|c|c|c|c|c|c|}
\hline \multirow[t]{2}{*}{ Zone } & \multirow[t]{2}{*}{ Layers } & \multirow{2}{*}{ Pre CXL, Mean (SD) } & \multicolumn{3}{|c|}{ Post CXL, Mean (SD) } \\
\hline & & & 3 Months & 6 Months & 12 Months \\
\hline \multirow[t]{3}{*}{$0-2 \mathrm{~mm}$} & Anterior & $24.2(0.8)$ & $39.7(20.8)$ & $28.5(5.4)$ & $31.5(14.2)$ \\
\hline & Central & $19.3(0.6)$ & $32.9(22.2)$ & $21.5(3.0)$ & $24.4(I I .1)$ \\
\hline & Posterior & I3.8(0.6) & $20.3(14.6)$ & 14.3 (I.2) & $16.2(6.8)$ \\
\hline \multirow[t]{3}{*}{$2-6 \mathrm{~mm}$} & Anterior & $19.8(0.8)$ & $33.8(20.6)$ & $23.5(4.4)$ & $27.8(16.4)$ \\
\hline & Central & $16.2(0.7)$ & $25.7(16.2)$ & I7.8 (I.7) & $21.0(10.7)$ \\
\hline & Posterior & $12.6(0.8)$ & 17.4 (II.4) & $12.9(1.1)$ & $14.4(5.3)$ \\
\hline \multirow[t]{3}{*}{$6-10 \mathrm{~mm}$} & Anterior & $18.5(1.9)$ & $23.3(6.4)$ & $19.1(2.9)$ & $26.09(11.0)$ \\
\hline & Central & $14.9(1.3)$ & I8.2(7.0) & $14.6(1.7)$ & $16.7(5.2)$ \\
\hline & Posterior & $12.2(1.2)$ & $14.3(5.4)$ & $12.0(1.7)$ & $12.7(2.6)$ \\
\hline
\end{tabular}


A
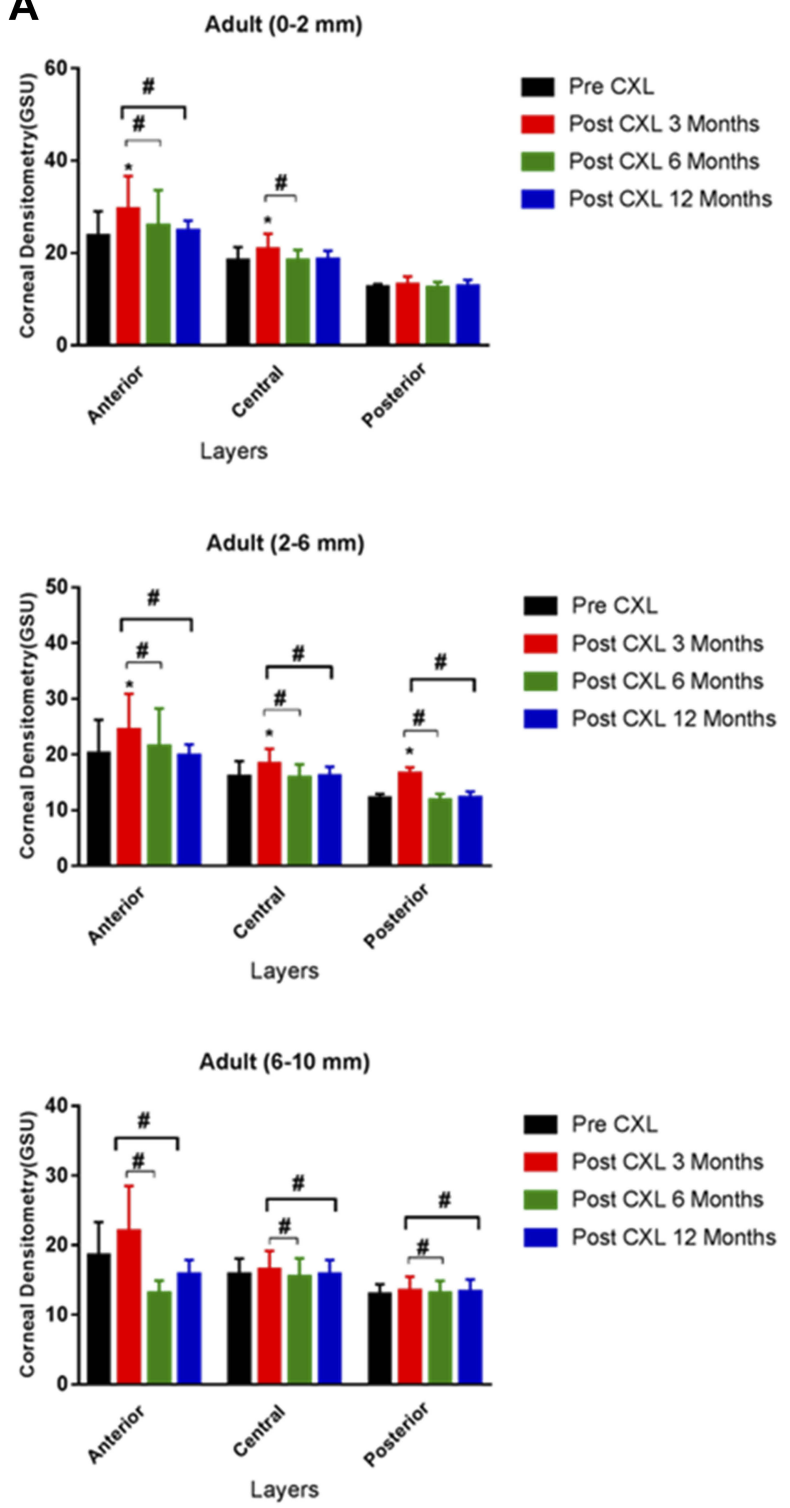

B
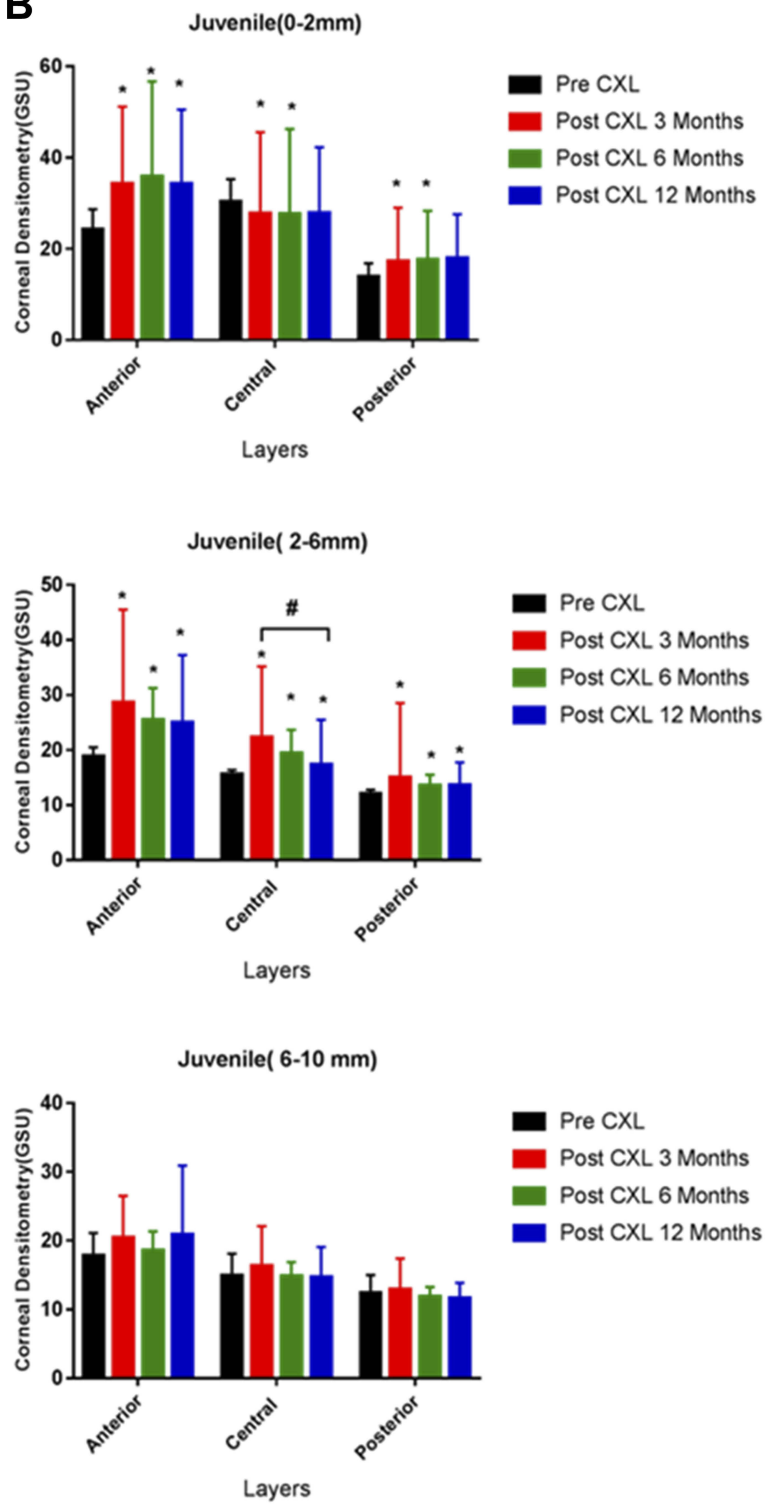

Figure I Corneal densitometry diversity at 3, 6 and 12 months post treatment for both groups. (A) Adult and (B) Juvenile in the different corneal zones and layers $(*$ significant from pre-treatment and \# represent significant from 3 months post treatment at level $\mathrm{P}<0.05$ ).

\section{Juvenile Group}

Corneal densitometry found differences at 3 months post treatment from the pre-treatment value. Statistical differences in $\mathrm{CD}$ were found in the $0-2 \mathrm{~mm}$ zone for anterior $(\mathrm{P}=0.01)$ central layers $(\mathrm{P}=0.02)$ and at zone $2-6 \mathrm{~mm}$ for anterior layer $(\mathrm{P}=0.009)$, and central layer $(\mathrm{P}=0.009)$.

Comparing post treatment at 6 months to pre-treatment result found a statically significant $C D$ in the $0-2 \mathrm{~mm}$ zone for the anterior layer $(\mathrm{P}=0.03)$, central layer $(\mathrm{P}=0.008)$ and posterior layer $(\mathrm{P}=0.03)$. Significant differences in $\mathrm{CD}$ were present in the $2-6 \mathrm{~mm}$ zone for the anterior layer $(\mathrm{P}=0.009)$ and the central layer $(\mathrm{P}=0.009)$.

At 12 months post treatment the value of $\mathrm{CD}$ found differed statistically from pre-treatment in the $0-2 \mathrm{~mm}$ zone for the anterior layer $(\mathrm{P}=0.03)$, in the $2-6 \mathrm{~mm}$ zone for anterior layer $(\mathrm{P}=0.01)$ and central layer $(\mathrm{P}=0.01)$.

At 12 months post treatment the value of $\mathrm{CD}$ found differed statistically from post treatment at 3 months in the $2-6 \mathrm{~mm}$ zone for the central layer $(\mathrm{P}=0.04)$. At 6 months post treatment the $\mathrm{CD}$ found no differences statistically 
from the post treatment at 3 months and 12 months in all corneal zones and layers (Figure 1B).

\section{Comparison of Both Groups}

The results of $\mathrm{CD}$ were compared between the adult and the juvenile groups at each time point and each corneal zone or layer. At pre-treatment a statistical significant difference was found in the $0-2 \mathrm{~mm}$ concentric zone for the central layer $(\mathrm{P}=0.022)$, posterior layer $(\mathrm{P}=0.013)$ and at full depth $(\mathrm{P}=0.04)$. The $\mathrm{CD}$ were found higher in Juvenile group in these entire layers pre-treatment vs adult group. However, at three months post treatment there were non-statistical differences between the two groups.

A significant statistical difference in $\mathrm{CD}$ was noted at six months post treatment in the $0-2 \mathrm{~mm}$ zone for the central layer $(\mathrm{P}=0.006)$, posterior layer $(\mathrm{P}=0.004)$ and full depth $(\mathrm{P}=0.026)$. There was also a statistically significant difference in $\mathrm{CD}$ readings in the anterior layer $(\mathrm{P}=0.017)$, central layer $(\mathrm{P}=0.013)$, posterior layer $(\mathrm{P}=0.013)$ and at full depth $(\mathrm{P}=0.011)$ within the $2-6 \mathrm{~mm}$ zone.
One year post treatment comparison found a statistical significant difference between both groups in the corneal zone $0-2 \mathrm{~mm}$ for the central layer $(\mathrm{P}=0.007)$, posterior layer $(\mathrm{P}=0.01)$ and at full depth $(\mathrm{P}=0.036)$. Another statistical significant difference found in the same post treatment time at $2-6 \mathrm{~mm}$ zone for the central layer $(\mathrm{P}=0.04)$.

No statistical differences were noted in CCT and thinnest area between pre-treatment and post-treatment at different measurement times within the groups and between both groups $(\mathrm{P}>0.05)$ (Figure 2).

There were no significant differences in BCVA between pre-treatment and all post treatment periods in the juvenile group $(\mathrm{P}<0.05)$ but there was a significant improvement in BCVA in the adult group at 6 months post treatment $(\mathrm{P}=0.02)$ and at 12 months post treatment $(\mathrm{P}=0.016)$ (Figure 3).

\section{Discussion}

One of the most common problems post-CXL in keratoconus is a significant increase in transient corneal haze. This haze formation can effectively restrict the treatment benefits by
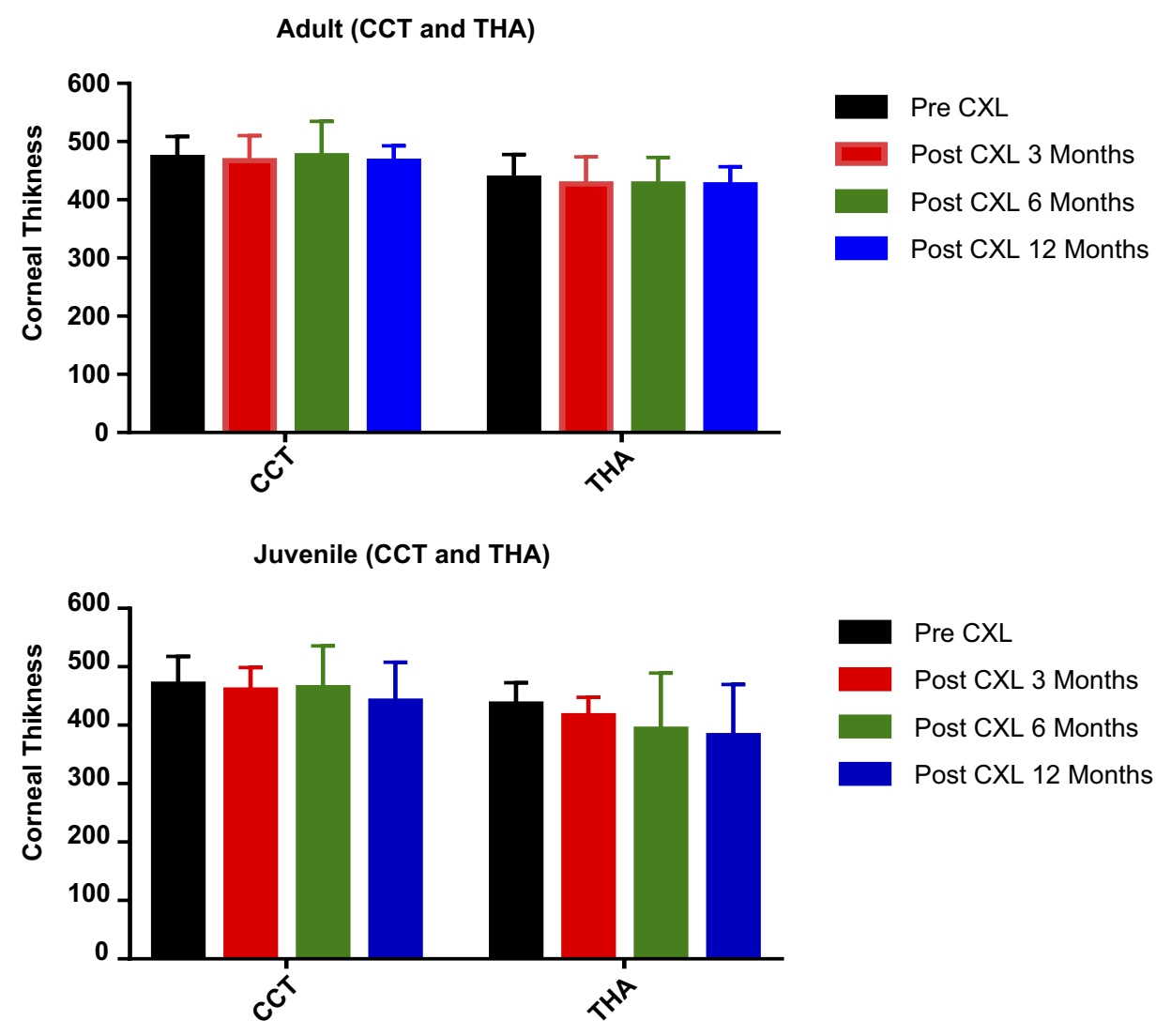

Figure 2 Corneal thickness (CCT) and thinnest area (THA) diversity between pre-treatment and all post-treatment period at each group. 

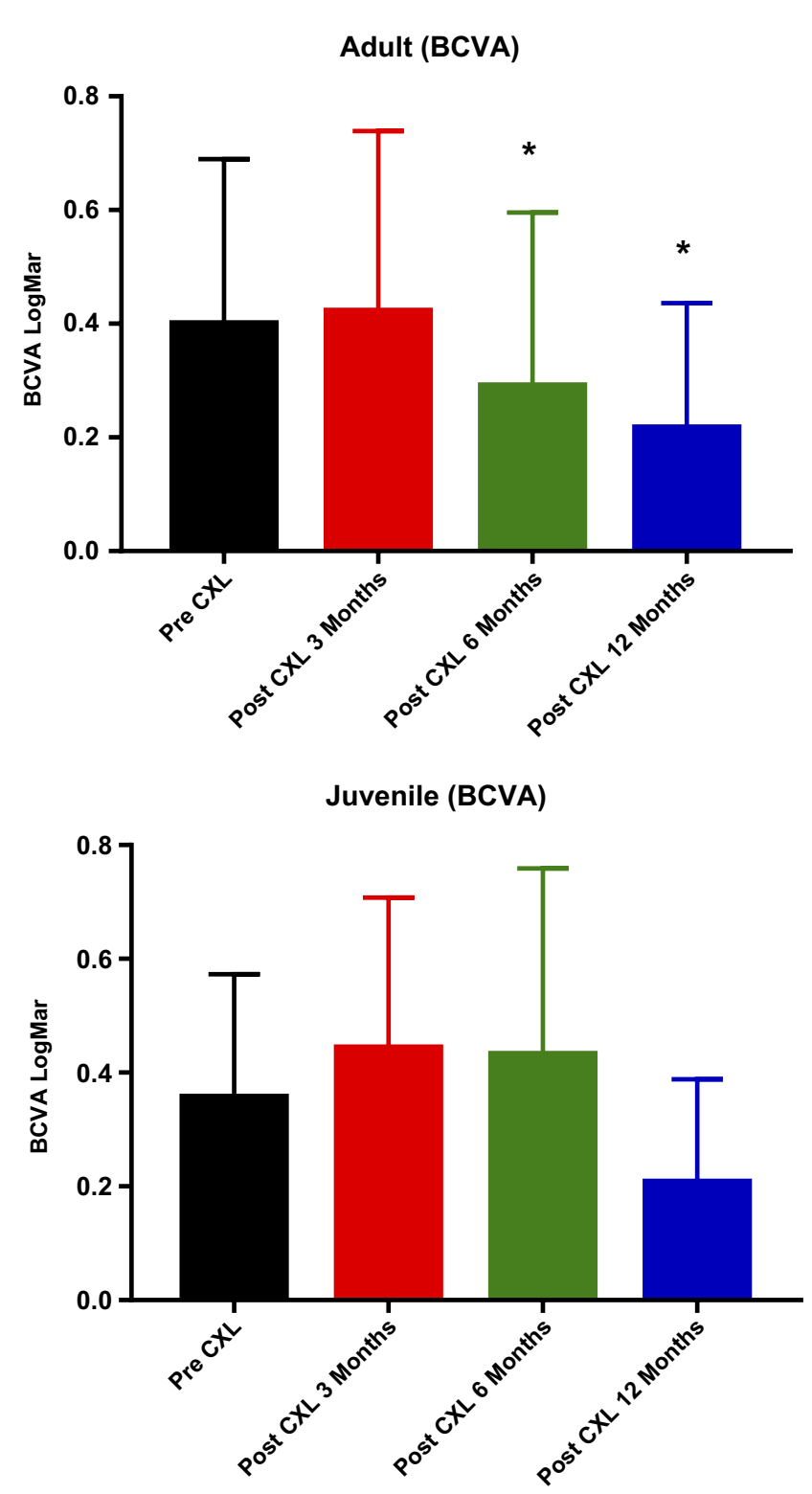

Figure 3 Diversity on BCVA between pre-treatment and post-treatment both in the adult and juvenile groups (*significant from pre-treatment at $\mathrm{P}<0.05$ ).

reducing corneal clarity which will ultimately effect BCVA outcome. $^{11,12}$ This study has investigated the nature of the haze objectively by using Pentacam Scheimpflug densitometry. This objective method has superiority over the clinical judging of the level of haze grade and may be useful in clarifying the role of post CXL haze. The aetiology of haze formation post CXL treatment is not fully understood and there are a few discrepancies in the literature. Haze formation after CXL is well known to differ from the haze seen after other procedures on the cornea including refractive surgery. ${ }^{13}$ Formation of new molecular bonds among collagen lamellae post treatment can cause disturbance of the structural organisation in the stroma which effects corneal clarity. ${ }^{14,15}$ An early report has shown that between 3 and 12 months post CXL treatment there is keratocyte repopulation and renewal of nerve plexuses along with lamellar compaction within the corneal stroma. ${ }^{16}$ Additionally, damage to keratocytes post $\mathrm{CXL}^{17}$ has been linked to haze formation in many studies. ${ }^{18}$

In this study, we found a statistically significant increase in CD in both groups between pre-treatment and 3 months post treatment. This increase in CD value was in the anterior and central layers for both corneal zones 0-2 $\mathrm{mm}$ and 2-6 $\mathrm{mm}$. This is as expected as the CXL treatment is predominantly focused within these areas of the cornea.

In the adult group, corneal clarity significantly improved at 6 months and 12 months when compared with corneal clarity at 3 months post treatment in the anterior and central layers for all 3 corneal zones. However, in the juvenile group statistically significant increases in CD were found at 6 months post treatment compared to pre-treatment for all corneal layers in the $0-2 \mathrm{~mm}$ zone and in the anterior and central layers within the 2-6 mm zone. At 12 months post treatment compared to pre-treatment statistically significant high $\mathrm{CD}$ was found in the anterior layer of $0-2 \mathrm{~mm}$ zone and anterior and central layers within the $2-6 \mathrm{~mm}$ zone. A statistically significant improvement in corneal clarity was noticed at 12 months post treatment compared to 3 months post treatment at the central layer of zone2-6mm. It has been proposed by Greenstein et $\mathrm{al}^{6}$ that $\mathrm{CD}$ increases between 1 and 3 months and then from the 3rd month through to the 6th month, clarity improvement is witnessed and CXL-correlated corneal haze appears to decrease significantly. Our study agrees with these results but only for adult group and not the juvenile patients.

Our results show that there is a significant difference in improvement of corneal clarity post CXL treatment between adult and juvenile keratoconus patients. Comparative analysis of both groups reveals that two groups have significantly different corneal haze profiles post CXL. This was evident at six months post treatment for both the central and posterior layers in the $0-2 \mathrm{~mm}$ zone and for all layers in the $2-6 \mathrm{~mm}$ zone. One-year post treatment significant differences in corneal clarity between both groups were found in both central and posterior layers in the $0-2 \mathrm{~mm}$ zone and in the central layer in the 2-6 mm zone. Divergence between the adult and juveniles keratoconus groups could be an effect of age as reports show that $\mathrm{CD}$ in healthy eyes increased with age in adults. ${ }^{19,20}$ CXL outcomes report that adult patients have a better outcome of functional and morphological criterion 
than juvenile patients. ${ }^{21}$ This divergence could be linked to the possible stimulation of differing activation pathways on keratocytes post-treatment ${ }^{22,23}$ which could have differing duration between the two groups. Differences in improvement between adult and juvenile groups could be influenced by corneal remodelling and wound healing process both of which play important roles. ${ }^{24,25}$

Our result showed that the maximum effect of haze following CXL treatment was in the corneal centre 0-6mm rather than in the periphery which agrees with earlier reported studies on corneal densitometry in keratoconus. ${ }^{26}$ The anterior layer in $0-2 \mathrm{~mm}$ zone has the highest densitometry level after the treatment because it received maximum treatment. ${ }^{27}$ In addition, the age of the participants could have an impact in corneal clarity changes. ${ }^{20,28}$ However, despite the common belief that $\mathrm{CXL}$ is a safe technique in children the positive effect of the treatment does not last as long in comparison to adults. ${ }^{29}$

This study did not find any significant differences in the BCVA for pre and post treatment for either group. These results supported earlier reports of a poor correlation between haze and visual acuity. ${ }^{6}$ However, a study looking at the changes in BCVA between pre-treatment and post-treatment in adult keratoconus showed that BCVA improved significantly between 6 and 12 months post-treatment. ${ }^{2}$ In the juvenile group, there was no significant improvement or diversity of BCVA at 12 months post-treatment from pre-treatment. ${ }^{30}$ This study could not find any differences in corneal thickness and thinnest area between groups and within each group which agree with the results of Shen et al. ${ }^{31}$

In conclusion, haze levels increase after CXL differing in severity in different corneal zones and between the juvenile and adult keratoconus. The 0-2 $\mathrm{mm}$ and 2-6 $\mathrm{mm}$ zones were found to be the most affected area post treatment. Corneal haze reached its maximum level at three months after treatment then appears to differ significantly in improvement level between adult and juvenile groups, with the latter not returning to pre-treatment clarity in the most anteriorly central zone in juvenile group by 12 months. Longer follow-up may need to evaluate if the effect is permanent.

\section{Compliance with Ethical Standards}

All procedures performed in studies involving human participants were in accordance with the ethical standards of the institutional and/or national research committee and with the 1964 Helsinki declaration and its later amendments or comparable ethical standards. Informed consent: Informed consent was obtained from all individual participants included in the study. This article does not contain any studies with animals performed by any of the authors.

\section{Acknowledgment}

The authors thank the Manchester Royal Eye Hospital (corneal clinic) for supporting patient's recruitments for this study. Supported by Armed Forces Medical Services, Ministry of Defence, Riyadh, Saudi Arabia. Part of the data has been presented at EVER 2017, Nice, France.

\section{Disclosure}

The authors report no conflicts of interest in this work.

\section{References}

1. Wollensak G. Crosslinking treatment of progressive keratoconus: new hope. Curr Opin Ophthalmol. 2006;17(4):356-360.

2. Raiskup-Wolf F, Hoyer A, Spoerl E, Pillunat LE. Collagen crosslinking with riboflavin and ultraviolet-A light in keratoconus: long-term results. J Cataract Refract Surg. 2008;34(5):796-801.

3. Wollensak G, Spoerl E, Seiler T. Riboflavin/ultraviolet-A-induced collagen crosslinking for the treatment of keratoconus. $\mathrm{Am}$ J Ophthalmol. 2003;135(5):620-627.

4. Spörl E, Huhle M, Kasper M, Seiler T. Increased rigidity of the cornea caused by intrastromal cross-linking. Der Ophthalmologe. 1997;94(12):902-906.

5. Spoerl E, Mrochen M, Sliney D, Trokel S, Seiler T. Safety of UVA-riboflavin cross-linking of the cornea. Cornea. 2007;26(4):385-389.

6. Greenstein SA, Fry KL, Bhatt J, Hersh PS. Natural history of corneal haze after collagen crosslinking for keratoconus and corneal ectasia: scheimpflug and biomicroscopic analysis. J Catar Refract Surg. 2010;36(12):2105-2114.

7. Spoerl E, Wollensak G, Dittert -D-D, Seiler T. Thermomechanical behavior of collagen-cross-linked porcine cornea. Ophthalmologica. 2004;218(2):136-140.

8. Koller T, Mrochen M, Seiler T. Complication and failure rates after corneal crosslinking. J Cataract Refract Surg. 2009;35(8):1358-1362.

9. Caporossi A, Mazzotta C, Baiocchi S, Caporossi T. Long-term results of riboflavin ultraviolet A corneal collagen cross-linking for keratoconus in Italy: the Siena eye cross study. Am J Ophthalmol. 2010;149 (4):585-593

10. Herrmann C, Hammer T, Duncker G. Haze-bildung nach vernetzungstherapie bei keratokonus. Der Ophthalmologe. 2008;105 (5):485-487.

11. Kanellopoulos AJ. Comparison of sequential vs same-day simultaneous collagen cross-linking and topography-guided PRK for treatment of keratoconus. J Refract Surg. 2009;25(9):S812-S818.

12. Alfonso JF, Fernández-Vega L, Lisa C, Fernandes P, GonzálezMéijome JM, Montés-Micó R. Collagen copolymer toric posterior chamber phakic intraocular lens in eyes with keratoconus. J Catar Refract Surg. 2010;36(6):906-916.

13. Møller-Pedersen T, Cavanagh HD, Petroll WM, Jester JV. Stromal wound healing explains refractive instability and haze development after photorefractive keratectomy: a 1-year confocal microscopic study. Ophthalmology. 2000;107(7):1235-1245.

14. Gutiérrez R, Lopez I, Villa-Collar C, González-Méijome JM. Corneal transparency after cross-linking for keratoconus: 1-year follow-up. $J$ Refract Surg. 2012;28(11):781-785. 
15. Wollensak G, Wilsch M, Spoerl E, Seiler T. Collagen fiber diameter in the rabbit cornea after collagen crosslinking by riboflavin/UVA. Cornea. 2004;23(5):503-507.

16. Anayol MA, Sekeroglu MA, Ceran BB, Dogan M, Gunaydin S, Yilmazbas P. Quantitative assessment of corneal clarity in keratoconus: a case control study of corneal densitometry. Eur J Ophthalmol. 2016;26(1):18-23.

17. Ringvold A, Davanger M. Changes in the rabbit corneal stroma caused by UV-radiation. Acta Ophthalmol (Copenh). 1985;63(5):601-606.

18. Mazzotta C, Balestrazzi A, Baiocchi S, Traversi C, Caporossi A. Stromal haze after combined riboflavin-UVA corneal collagen cross-linking in keratoconus: in vivo confocal microscopic evaluation. Clin Experiment Ophthalmol. 2007;35(6):580-582.

19. Dhubhghaill SN, Rozema JJ, Jongenelen S, Hidalgo IR, Zakaria N, Tassignon M-J. Normative values for corneal densitometry analysis by scheimpflug optical assessmentcorneal densitometry in the normal population. Invest Ophthalmol Vis Sci. 2014;55(1):162-168.

20. Alzahrani K, Carley F, Brahma A, Morley D, Hillarby MC. Corneal clarity measurements in healthy volunteers across different age groups: observational study. Medicine. 2017;96(46):e8563.

21. Vinciguerra R, Romano MR, Camesasca FI, et al. Corneal cross-linking as a treatment for keratoconus: four-year morphologic and clinical outcomes with respect to patient age. Ophthalmology. 2013;120(5):908-916

22. Gardner SJ, White N, Albon J, Knupp C, Kamma-Lorger CS, Meek KM. Measuring the refractive index of bovine corneal stromal cells using quantitative phase imaging. Biophys J. 2015;109(8):1592-1599.
23. Meek K, Leonard D, Connon C, Dennis S, Khan S. Transparency, swelling and scarring in the corneal stroma. Eye. 2003;17(8):927-936.

24. Wollensak G, Spoerl E, Wilsch M, Seiler T. Keratocyte apoptosis after corneal collagen cross-linking using riboflavin/UVA treatment. Cornea. 2004;23(1):43-49.

25. Wilson SE, Kim W-J. Keratocyte apoptosis: implications on corneal wound healing, tissue organization, and disease. Invest Ophthalmol Vis Sc. 1998;39(2):220-226.

26. Lopes B, Ramos I, Ambrósio JR. Corneal densitometry in keratoconus. Cornea. 2014;33(12):1282-1286.

27. Pircher N, Pachala M, Prager F, Pieh S, Schmidinger G. Changes in straylight and densitometry values after corneal collagen crosslinking. J Catar Refract Surg. 2015;41(5):1038-1043.

28. Buzzonetti L, Petrocelli G. Transepithelial corneal cross-linking in pediatric patients: early results. J Refract Surg. 2012;28(11):763-767.

29. Chatzis N, Hafezi F. Progression of keratoconus and efficacy of pediatric corneal collagen cross-linking in children and adolescents. $J$ Refract Surg. 2012;28(11):753-758.

30. Efron N, Hollingsworth JG. New perspectives on keratoconus as revealed by corneal confocal microscopy. Clin Exp Optom. 2008;91(1):34-55.

31. Shen Y, Jian W, Sun L, et al. One-year follow-up of changes in corneal densitometry after accelerated $(45 \mathrm{~mW} / \mathrm{cm} 2)$ transepithelial corneal collagen cross-linking for keratoconus: a retrospective study. Cornea. 2016;35(11):1434.

\section{Clinical Optometry}

\section{Publish your work in this journal}

Clinical Optometry is an international, peer-reviewed, open access journal publishing original research, basic science, clinical and epidemiological studies, reviews and evaluations on clinical optometry. All aspects of patient care are addressed within the journal as well as the practice of optometry including economic and business analyses. Basic and clinical research papers are published that cover

\section{Dovepress}

all aspects of optics, refraction and its application to the theory and practice of optometry. The manuscript management system is completely online and includes a very quick and fair peer-review system, which is all easy to use. Visit http://www.dovepress.com/ testimonials.php to read real quotes from published authors. 